\title{
Sulfuric Acid-Containing Mist
}

National Cancer Institute

\section{Source}

National Cancer Institute. Sulfuric Acid-Containing Mist. NCI Thesaurus. Code C44449.

A mist is defined as a liquid aerosol formed by condensation of a vapor or by atomization of a liquid. Sulfuric-acid containing mist may be generated during the production or use of sulfuric acid, sulfur trioxide, or oleum. Acute inhalation exposure to this aerosol can result in respiratory tract irritation. Ingestion of this mist can burn the mouth, throat and stomach; it may ultimately result in death. Contact with sulfuric acid containing mist can both irritate and burn the eyes and skin. It is known to be a human carcinogen. 